\title{
Introducing the Journal of Compassionate Health Care
}

Sue Shea ${ }^{1,2^{*}}$ and Christos Lionis ${ }^{1}$

The inspiration for this new open access journal, Journal of Compassionate Health Care emerged from the apparent need to restore humanity to healthcare, particularly within a period of austerity that has been affecting many countries. In 2011, we organized a successful Symposium on the topic of compassion in health care [1] at the University of Greenwich, UK, bringing together key people from various backgrounds with an interest in moving forward with the science and art of compassion. From this Symposium, we realized that people are united in the importance of developing compassionate health care settings, through a multidisciplinary approach.

This editorial seeks to enhance the broad concept of compassionate health care, in theory and in practice by inviting practitioners and researchers in health care to consider compassionate care as a core subject in their interest and research priorities. The journal aims to provide a vehicle for bringing together multidisciplinary perspectives, research and initiatives concerning the concept of compassionate health care, which has recently received much attention and interest. Here we explain the motivation behind the new open access journal, and we invite health care practitioners and researchers to join us in promoting the Journal's aims and scope.

\section{Compassion in health care}

Concerns that health care often fails at a fundamental level have been recently escalated in the UK since the publication of the Francis Report [2], which drew international attention to the lack of the most basic elements of care. In the US health care systems, similar problems have also been reported including "escalating costs, medical errors, inconsistent results and, according to a new national survey, a lack of compassion" [3]. Evidence suggests that the component parts of compassion such as kindness, empathy, attention to basic needs, and attention to dignity,

\footnotetext{
* Correspondence: sueshea1@otenet.gr

${ }^{1}$ Clinic of Social and Family Medicine, Department of Social Medicine, Faculty of Medicine, University of Crete, P.O. Box 2208, 71003 Heraklion, Crete ${ }^{2}$ Research Consultant, Whitstable, UK
}

are crucial in alleviating pain, prompting fast recovery from acute illness, assisting in the management of chronic illness, and relieving anxiety. Other physiological benefits of compassion have also been reported, for example alteration in heart rhythm and brain function in both the person providing and the person receiving compassion [4-6].

For compassion to succeed it is important to consider the health care setting as a whole, including organizational factors. Team work, Health Care Professional (HCP) self care and understanding, and a compassionate approach between HCPs towards each other may all contribute to the overall patient and HCP experience. HCPs are often under strain from large amounts of paperwork and other factors, and burn-out is a growing issue in general practitioners [7]. Thus if HCPs do not receive adequate support themselves, it would be more difficult for them to show compassion towards their patients.

To bring compassion back into the US health care system, the Schwartz Center for Compassionate Healthcare (www.theschwartzcenter.org) [8] has developed the Schwartz Center Rounds ${ }^{\circ}$, which are designed for staff to come together once a month to discuss the non-clinical aspects of their work, including emotional and social challenges. The Schwartz Center Rounds are currently being piloted by the The Point of Care programme in the UK [9].

Compassion may also be viewed as a vehicle for enhancing quality and reducing the cost of health care services. In times of austerity, as many countries are currently experiencing, health care is deeply affected by cut-backs. The current economic crisis has seriously impacted health and welfare care systems [10], but the concept of compassion has yet to receive the attention that it deserves.

\section{Launching the journal of compassionate health care}

With the launch of this new journal, we aim to address the concepts surrounding the notion of compassion and we hope that it will contribute to broader discussions of such within a wider setting. Beyond the fact that compassion is identified as a great virtue, there are many concepts that are affiliated with it, and among them accountability 
has been defined as having a central role in applying a human rights framework to health [11]. Thus, compassion may be seen as incorporating many concepts that are the focus of current health care systems including patient safety and rights, quality of health care and cost of health care services.

There is a rapidly growing interest in the concept of compassionate care at a global level, although the subject is still relatively new and developing with regards to the medical and nursing curricula. Thus, an issue that introduces some controversy within the subject of compassionate care is to what extent compassion as a virtue can be taught. Although most HCPs enter their profession with compassion, it is possible that the scientific nature of medical/nurse training may lead to a decrease in compassion. As such, sustaining compassion as a virtue through support and tuition is a field requiring prompt attention. Emerging empirical and observational data suggest that the introduction of courses on compassionate care within medical and nurse training is both feasible and welcome $[12,13]$. Research focusing on the longer term impact of training in compassionate care and its effects on the wellbeing and health outcomes of both patients and HCPs could be valuable.

The launch contains articles reflecting a wide range of issues related to compassionate health care. Robin Youngson [14] describes a workshop which is designed in accordance to the principles of positive psychology and appreciative inquiry, and which elicits stories of deep connection and caring among the participants, motivating them to strengthen their own caring and compassion. It is argued that this approach may be more effective than top-down policies or regulations. Chapin et al. [15] report on a pilot study which utilises a compassion meditation intervention for people with chronic pain. Their work concludes that compassion meditation may be a useful treatment for reducing pain severity and anger and for increasing chronic pain acceptance. Fitzgerald et al. [16] evaluate a project implementing the CARE Approach within primary and community care settings, which aims to enhance empathic, person-centred communication in health care encounters. These authors conclude that this approach appears to be useful in primary and community care, and that it is feasible to deliver this approach in peer facilitated learning groups.

On behalf of the editors and editorial board members, welcome to the Journal of Compassionate Health Care. In conclusion, we look forward to promoting discussion, research and activities across the broad and diverse field of compassionate health care.

\section{References}

1. Shea S, Wynyard R, West E, Lionis C: Reaching a consensus in defining and moving forward with the science and art of compassion in healthcare. J Holist Health Care 2011, 8(3):58-60.

2. Francis RQC: Report of the mid staffordshire NHS foundation trust public inquiry. House of Commons: Stationary Office 2013, Vols 1-3.

3. Nauert R Cited in http://psychcentral.com/news/2011/09/09/compassionmissing-in-american-health-care/29295.html (Accessed May 2014).

4. Fogarty LA, Curbow BA, Wingard JR, McDonnell K, Somerfield MR: Can 40 seconds of compassion reduced patient anxiety? J Clin Oncol 1999, 17(1):371

5. Science Daily: http://www.sciencedaily.com/releases/2012/12/121203145952. htm (Accessed June 2014).

6. Shaltout HA, Tooze JA, Rosenberger MS, Kemper KJ: Time, touch, and compassion: effects on autonomic nervous system and well-being. Explore 2012, 8:177-184.

7. Pulse: 2013. http://www.pulsetoday.co.uk/your-practice/battling-burnout/ revealed-half-of-gps-at-high-risk-ofburnout/20003157.article\#.VEfkeCKUfZ0 (Accessed July 2014)

8. Schwartz Center for Compassionate Healthcare. [available at: www.theschwartzcenter.org].

9. Goodrich J: Supporting hospital staff to deliver compassionate care: Do Schwartz center rounds work in english hospitals? J R Soc Med 2012, 105(3):117-122.

10. Stuckler D, Basu S: The Body Economic. Allen Lane London: Why Austerity Kills; 2013

11. Yamin AE: Beyond compassion: the central role of accountability in applying a human rights framework to health. Health Hum Rights 2008, 10(2):1-20.

12. Adamson E, Dewar B: Compassion in the nursing curriculum: making it more explicit. J Holist Healthc 2011, 8(3):42-45.

13. Lionis $C$, Shea S, Markarki A: Introducing and implementing a compassionate care elective for medical students in Crete. J Holist Healthc 2011, 8(3):38-41.

14. Youngson R: Re-inspiring compassionate caring: the reawakening purpose workshop. J Compassionate Health Care 2014, 1:1.

15. Chapin HL, Darnall BD, Seppala EM, Doty JR, Hah JM, Mackey SC: Pilot study of a compassion meditation intervention in chronic pain. J Compassionate Health Care 2014, 1:4

16. Fitzgerald NM, Heywood S, Bikker A, Mercer SW: Enhancing empathy in healthcare: mixed-method evaluation of a pilot project implementing the CARE Approach in primary and community care settings in Scotland. J Compassionate Health Care 2014, 1:6.

doi:10.1186/s40639-014-0007-7

Cite this article as: Shea and Lionis: Introducing the Journal of

Compassionate Health Care. Journal of Compassionate Health Care 2014 1:7.

\section{Submit your next manuscript to BioMed Central and take full advantage of:}

- Convenient online submission

- Thorough peer review

- No space constraints or color figure charges

- Immediate publication on acceptance

- Inclusion in PubMed, CAS, Scopus and Google Scholar

- Research which is freely available for redistribution
C Biomed Central 